\title{
The effect of hydrophobic (silane) treatment on concrete durability characteristics
}

\author{
Haris Sohawon ${ }^{1, *}$, Hans Beushausen ${ }^{1}$ \\ ${ }^{1}$ CoMSIRU, Department of Civil Engineering, University of Cape Town, South Africa
}

\begin{abstract}
Hydrophobic (silane) impregnation represents a cost-effective way to increase the durability of concrete structures in cases where insufficient design cover quality and depth have been achieved. The water repellent product lines the internal capillary pore structure and provides a waterrepellent concrete surface. Thus, the risk of reinforcement corrosion initiation and subsequent deterioration can be reduced as the ingress of water-dissolved aggressive species (chlorides) is minimised or prevented. The purpose of this study was to investigate the effect of silane impregnation on durability indicators, including penetrability tests and chloride ingress (bulk diffusion). The results indicate that silane impregnation reduces capillary absorption and conductivity of chloride ions. Similarly, chloride ingress in the treated concrete mixes was suppressed.
\end{abstract}

\section{Introduction}

Cover concrete represents the primary barrier against the ingress of aggressive agents towards the reinforcing steel and several design codes define cover depths according to particular environmental classes [1]. The thickness and quality of this zone is largely dependent on on-site quality control and curing conditions respectively [2]. As the modern construction industry is under the perpetual constraints of time and money, quality control is often neglected on site, resulting in sometimes poor execution and outcome of works. Hence, the design cover depth and quality are not achieved due to improper placing, compaction and curing of in situ concrete. In this respect, considerable research has been undertaken to identify suitable solutions to avoid premature deterioration and extend the service life of reinforced concrete. Surface treatment represents a preventative measure to protect new and existing structures from environmental attack and reduce the risk of associated reinforcement corrosion. The aim of surface treatment is to reduce the concrete cover's penetrability to aggressive substances. Hydrophobic impregnation (penetrant pore liner) is one type of surface treatment that has the ability to reduce the capillary absorption of water containing dissolved deleterious species (chlorides) and thus delay the initiation of rebar corrosion $[1,3]$.

Hydrophobic impregnations are products that are typically applied on the surface of a concrete substrate (as an invisible film) to reduce the uptake of water and dissolved aggressive species. The hydrophobic agent is applied by spraying or brushing, depending on its viscosity. The material is transported into the pore structure through capillary action. Cream based hydrophobic treatments have a longer drying time relative to liquid systems and this usually result in superior penetration efficiency, and thus higher protective potential. The main advantage of hydrophobic treatment is that it provides a water-repellent surface without affecting the appearance of the concrete and does not hinder the movement of water vapour in and out of the concrete $[4,5]$.

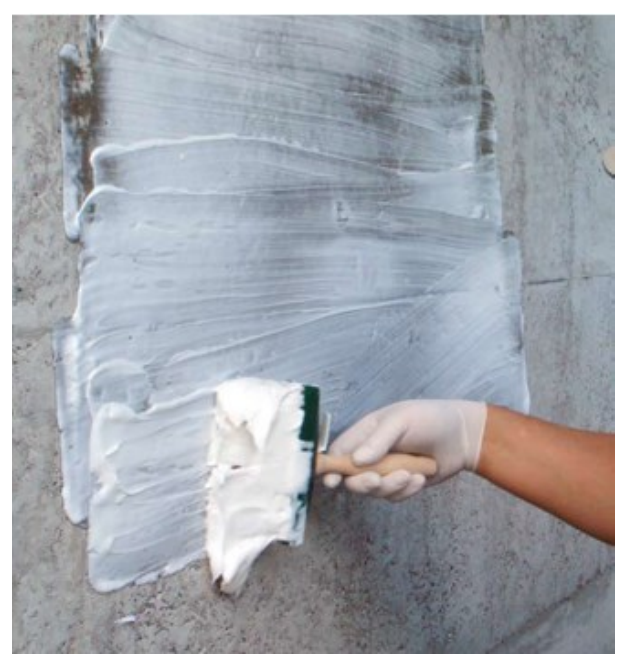

Fig. 1. Silane based cream [6]

Liquid water is rapidly transported in non-saturated pores by capillary action, and the rate of absorption is a function of the surface tension, the density and viscosity of the liquid, contact angle between the liquid and pore walls, and the pore size opening. In normal concrete, the contact angle $(\theta)$ is low $\left(<90^{\circ}\right)$ because of molecular attraction between the cement paste and water (hydrophilic behaviour). The drop of water will typically

* Corresponding author: shwhar001@myuct.ac.za 
Table 1. Mix designs, slump values and compressive strengths

\begin{tabular}{|c|c|c|c|c|c|c|c|c|}
\hline & Mix 1 & Mix 2 & Mix 3 & Mix 4 & Mix 5 & Mix 6 & Mix 7 & Mix 8 \\
\hline Material $\left(\mathrm{kg} / \mathrm{m}^{3}\right)$ & CEM I & CEM I & $30 \%$ FA & $30 \%$ FA & $\begin{array}{c}50 \% \\
\text { GGCS }\end{array}$ & $\begin{array}{c}50 \% \\
\text { GGCS }\end{array}$ & $\begin{array}{l}\text { CEM } \\
\text { III/B }\end{array}$ & $\begin{array}{l}\text { CEM } \\
\text { III/B }\end{array}$ \\
\hline Water to binder ratio (w/b) & 0.45 & 0.60 & 0.45 & 0.60 & 0.45 & 0.60 & 0.45 & 0.60 \\
\hline $\begin{array}{c}\text { Cement } \\
(\text { CEM III/B 42.5N) }\end{array}$ & - & - & - & - & - & - & 411 & 308 \\
\hline $\begin{array}{c}\text { Cement } \\
\text { (CEM I 52.5N) }\end{array}$ & 411 & 308 & 288 & 216 & 206 & 154 & - & - \\
\hline Extender (FA) & - & - & 123 & 93 & - & - & - & - \\
\hline Extender (GGCS) & - & - & - & - & 206 & 154 & - & - \\
\hline $\begin{array}{l}\text { Fine aggregate } \\
\text { (Crusher sand) }\end{array}$ & 426 & 472 & 406 & 457 & 419 & 467 & 413 & 463 \\
\hline $\begin{array}{c}\text { Fine aggregate } \\
\text { (Dune sand) }\end{array}$ & 426 & 472 & 406 & 457 & 419 & 467 & 413 & 463 \\
\hline $\begin{array}{c}\text { Coarse aggregate } \\
\text { (19-mm Greywacke) }\end{array}$ & 1040 & 1040 & 1040 & 1040 & 1040 & 1040 & 1040 & 1040 \\
\hline Water & 185 & 185 & 185 & 185 & 185 & 185 & 185 & 185 \\
\hline Total binder $\left(\mathrm{kg} / \mathrm{m}^{3}\right)$ & 411 & 308 & 411 & 308 & 411 & 308 & 411 & 308 \\
\hline Fly-ash content (\%) & - & - & 30 & 30 & - & - & - & - \\
\hline GGCS content $(\%)$ & - & - & - & - & 50 & 50 & - & - \\
\hline Slump (mm) & 70 & 60 & 90 & 65 & 75 & 60 & 70 & 70 \\
\hline fc, 28-d (MPa) & 66.7 & 47.7 & 55.3 & 35.6 & 63.1 & 49.2 & 58.5 & 45.4 \\
\hline
\end{tabular}

spread flat on the surface followed by capillary rise in the pore structure, resulting in the suction of water.

The use of a hydrophobic impregnation weakens the molecular attraction between water and concrete; as silane molecules cover the capillary walls, they become devoid of ionic electrical charges and polar molecules such as water are no longer attracted to the concrete surface. The contact angle is thus increased $\left(>90^{\circ}\right)$, resulting in a spherical shape and subsequent negative capillary rise (the level of the liquid in the pores is lower than that of the surrounding liquid - Figure 2 [1,7].
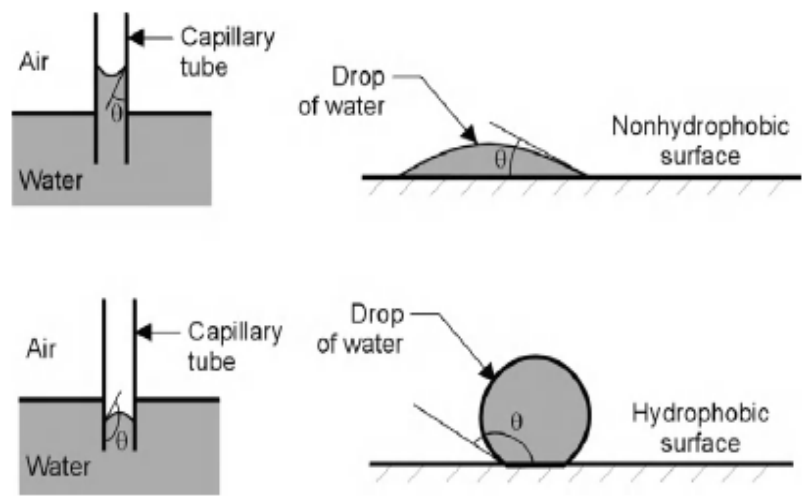

Fig. 2. Interaction between water and concrete surface for untreated and treated surfaces [1]

Silane, siloxane or a mixture of these two components are typically used as hydrophobic impregnation products. Silane molecules are smaller $\left(1 \times 10^{-6}-1.5 \times 10^{-6} \mathrm{~mm}\right.$ diameter) relative to siloxane molecules $\left(1.5 \times 10^{-6}-7.5\right.$ $\mathrm{x} 10^{-6} \mathrm{~mm}$ diameter) and hence, in general greater penetration depth is obtained with the use of pure silane products [8]. However, a smaller molecular size correlates to higher volatility. Pure silane is hence used mostly in gel consistency as this enables the application of thick layers of water repellent product on vertical surfaces without slumping or sagging $[6,8]$.

\section{Methodology}

\subsection{Mix design}

Two water to binder ratios (w/b 0.45 and w/b 0.60$)$ and four binder types were selected (CEM I 52.5N, Fly-ash (FA), Ground granulated Corex slag (GGCS) and CEM III/B $42.5 \mathrm{~N}$ ). Hence a total of 8 concrete mixes were used. The concrete specimens were demoulded 24 hours after casting, wrapped in plastic sheeting and placed in an environmental room $\left(23 \pm 2{ }^{\circ} \mathrm{C}\right.$ temperature and $63 \pm 2 \%$ relative humidity). After $\overline{7}$ days, the plastic sheeting was removed, and the specimens were air cured under the aforementioned controlled environmental conditions until the age of 56 days. The mix design is shown in Table 1.

\subsection{Silane treatment}

Silane treatment was performed at the age of 28 days by applying Sikagard ${ }^{\mathbb{R}}-706$ Thixo [6] (a silane based water repellent impregnation cream) at a consumption rate of 
$400 \mathrm{~g} / \mathrm{m}^{2}$. The treated specimens were then placed in an environmental room (maintained at a temperature of $23 \pm$ $2{ }^{\circ} \mathrm{C}$ and relative humidity of $63 \pm 2 \%$ ) until the age of $5 \overline{6}$ days.

\subsection{Experimental investigations}

Compressive strength tests were carried out on three cubes $(100 \mathrm{~mm})$ of each mix, according to SANS 5863 (2006) [9]. Durability Index (DI) tests were performed on cut surfaces (for mix characterisation) and uncut surfaces (to assess the influence of silane impregnation on transport properties such as capillary water absorption and chloride conductivity). Oxygen Permeability Index (OPI), Water Sorptivity Index (WSI) and Chloride Conductivity Index (CCI) tests were carried out in accordance with SANS 3001-CO3-2 (2015) [10], the UCT DI test manual (2017) [11] and SANS 3001-CO3-3 (2015) [12] respectively.

The hydrophobic (silane) impregnation depth was measured 4 weeks after treatment. The indirect tensile splitting test was performed on two silane treated concrete cubes $(100 \mathrm{~mm})$ and water was sprayed on the internal surface. The hydrophobised part of concrete repelled any water while the untreated part showed darker coloration, due to water absorption (Figure 3). A Vernier caliper was used to take the measurements. The method used to measure the silane penetration depth follow the recommendations of BS EN 1504-2 [13].

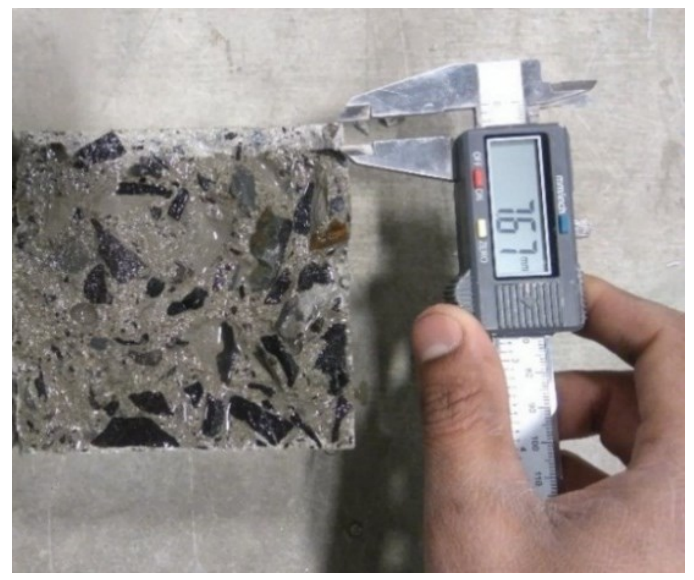

Fig. 3. Silane penetration depth measurement
Bulk diffusion tests were carried out in accordance with ASTM C1556 (2004) [14], starting at a sample age of 56 days. Six test specimens ( 3 treated $/ 3$ untreated) were used per mix. After the chloride exposure period, specimens were removed from the salt solution and cut into slices at suitable increments. These slices were pulverized and milled into approximately $10 \mathrm{~g}$ powder samples. A potentiometric titrator was used to determine the acid soluble chloride ion content, in accordance with ASTM C1152 (2012) [15].

\section{Results and discussions}

\subsection{Durability Indexes}

\subsubsection{Cut surfaces}

Durability Index tests (OPI, WSI and CCI) were performed on cut surfaces for mix characterisation purposes. All the concrete mixes (Mix 1-8) achieved OPI values between 9.90 and 10.67 , WSI values ranging from 4.2 to $7.8 \mathrm{~mm} / \mathrm{hr}^{0.5}$, and CCI values between 0.16 and 1.09 $\mathrm{mS} / \mathrm{cm}$ (Table 2). The OPI decreased while WSI and CCI values generally increased with a higher $\mathrm{w} / \mathrm{b}$ and this was attributed to an increase in porosity of the cement paste microstructure and larger number of interconnections between the pores which act as channels of flow in the cement paste [16]. This allowed greater permeation of oxygen gas, capillary absorption of liquids and migration of chloride ions respectively.

\subsubsection{Uncut surfaces}

The effect of the hydrophobic treatment on DI values was assessed on uncut (formwork) surfaces, to represent site conditions. According to the results, silane treated concrete recorded lower WSI (Figure 4) and CCI values (Figure 5) relative to untreated concrete. Hydrophobic (silane) impregnation chemically modifies the near surface zone of the concrete and reduces the capillary uptake of water. As the silane molecules bond and cover the capillary walls, the latter become devoid of ionic electrical charges and polar molecules such as water is no longer attracted to the concrete surface $[4,7,17]$.

Table 2. Durability Index test results (cut surfaces)

\begin{tabular}{|c|c|c|c|c|c|c|c|c|}
\hline Mix no & Mix 1 & Mix 2 & Mix 3 & Mix 4 & Mix 5 & Mix 6 & Mix 7 & Mix 8 \\
\hline Binder & CEM I & CEM I & $\mathbf{3 0 \%}$ FA & $\mathbf{3 0 \% ~ F A ~}$ & $\begin{array}{c}\mathbf{5 0} \% \\
\text { GGCS }\end{array}$ & $\begin{array}{c}\mathbf{5 0 \%} \\
\text { GGCS }\end{array}$ & $\begin{array}{c}\text { CEM } \\
\text { III/B }\end{array}$ & $\begin{array}{c}\text { CEM } \\
\text { III/B }\end{array}$ \\
\hline w/b & $\mathbf{0 . 4 5}$ & $\mathbf{0 . 6 0}$ & $\mathbf{0 . 4 5}$ & $\mathbf{0 . 6 0}$ & $\mathbf{0 . 4 5}$ & $\mathbf{0 . 6 0}$ & $\mathbf{0 . 4 5}$ & $\mathbf{0 . 6 0}$ \\
\hline OPI (log-scale) & 10.54 & 9.95 & 10.06 & 10.04 & 10.34 & 9.90 & 10.67 & 10.32 \\
\hline WSI (mm/hr (.5) $^{\text {W. }}$ & 5.7 & 6.8 & 7.8 & 7.5 & 4.2 & 5.5 & 7.1 & 7.2 \\
\hline CCI (mS/cm) & 0.58 & 1.09 & 0.66 & 0.98 & 0.16 & 0.25 & 0.16 & 0.28 \\
\hline Porosity (\%) & 9.0 & 11.9 & 9.5 & 10.9 & 7.3 & 8.8 & 7.7 & 9.8 \\
\hline
\end{tabular}




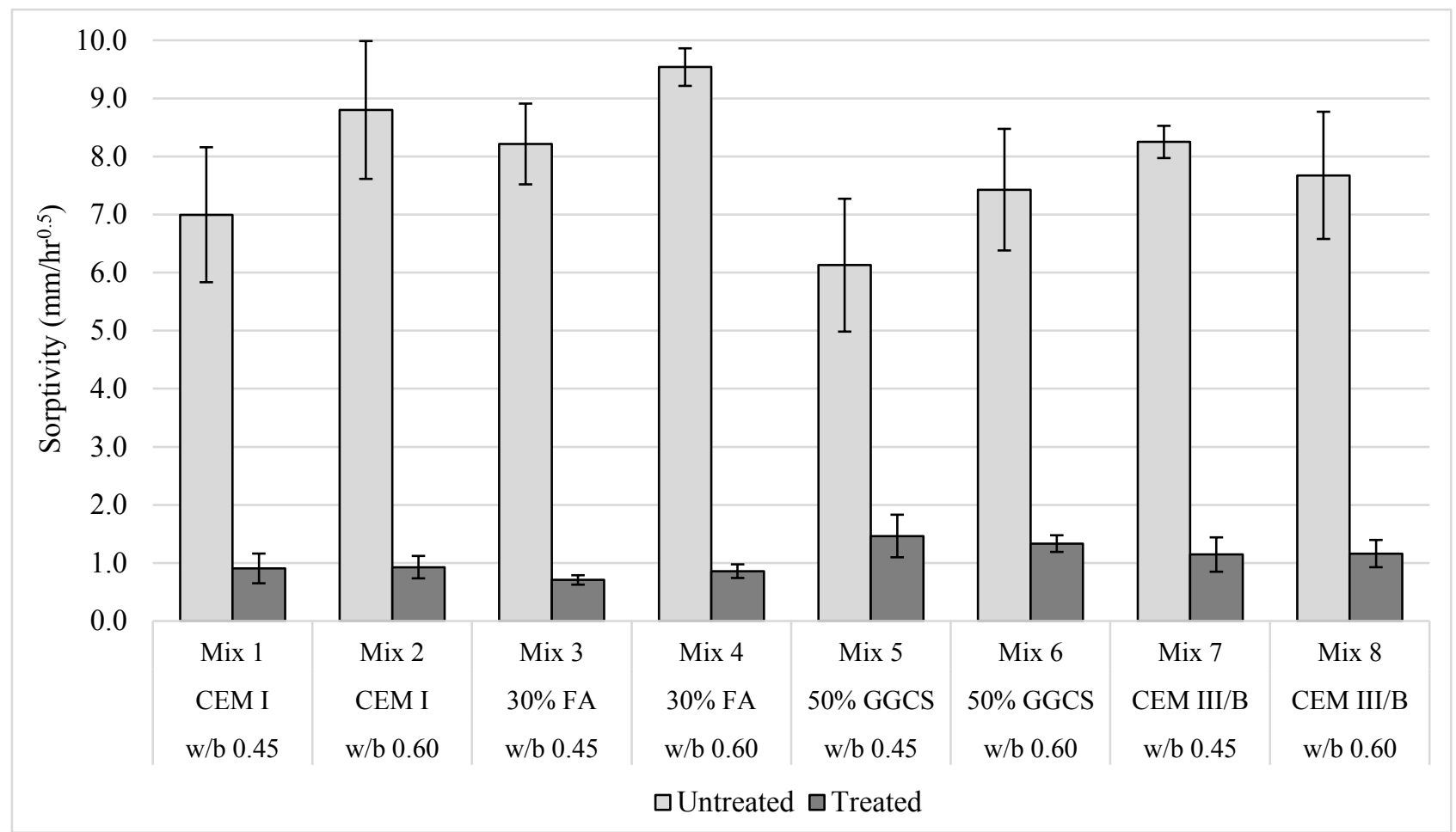

Fig. 4. Durability Index test results (uncut surfaces - WSI)

Migration of chloride ions was minimised as the capillary pores within the silane impregnated layer are less saturated relative to untreated concrete $[18,19]$.

\subsection{Silane penetration depth}

As expected, the silane penetration depth increased with a higher $\mathrm{w} / \mathrm{b}$ ratio (Figure 6). This was attributed to the higher capillary porosity of the cement paste microstructure which allowed deeper penetration of the water repellent product $[5,20]$. The effect of binder type for the w/b 0.60 mixes was unclear due to the overlapping of error bars but for the $\mathrm{w} / \mathrm{b} 0.45$ mixes, the inclusion of FA and GGBS (CEM III/B) increased and reduced the penetration depth respectively. It must be noted that a fixed silane consumption rate $\left(400 \mathrm{~g} / \mathrm{m}^{2}\right)$ was used for all the concrete mixes (Mix 1-8). In the case of in-situ structures, preliminary trials should be carried out to findthe consumption rate required to achieve sufficient penetration depth (typically 5-6 mm) [5]. The silane penetration depth $(\mathrm{mm})$ was also found to be highly related to the Oxygen Permeability Index (OPI/log-scale), as shown in Figure 7. Note that the measured OPI values ranged from about 9.90 to 10.67 , representing the negative log of the coefficient of permeability. Due to the logarithmic scale, a concrete with an OPI value of 9.90 is about 6 times more permeable, compared to a concrete with an OPI value of 10.67. The good correlation between OPI and silane penetration depth was explained by the fact that the penetration depth of the product is a function of the overall quality (interconnectedness, tortuosity of the capillary pore structure) of the near surface concrete and the OPI test evaluates these properties [21].

\subsection{Bulk diffusion}

The detailed bulk diffusion results are contained in [22]. An example for typical chloride ingress profiles is given in Figure 8. In general, silane treatment reduced the surface chloride concentration and the effect was most pronounced in the FA, GGCS, and CEM III/B mixes.

Similarly, the silane treated concrete had lower apparent chloride diffusion coefficients relative to the untreated concrete. As the chloride penetration and content is reduced within the near surface zone, the supply of chloride ions that can diffuse deeper into the concrete is smaller. Diffusion of chlorides is also significantly slowed down as the capillary pores are less saturated in the silane impregnated (treated) concrete $[18,19]$. 


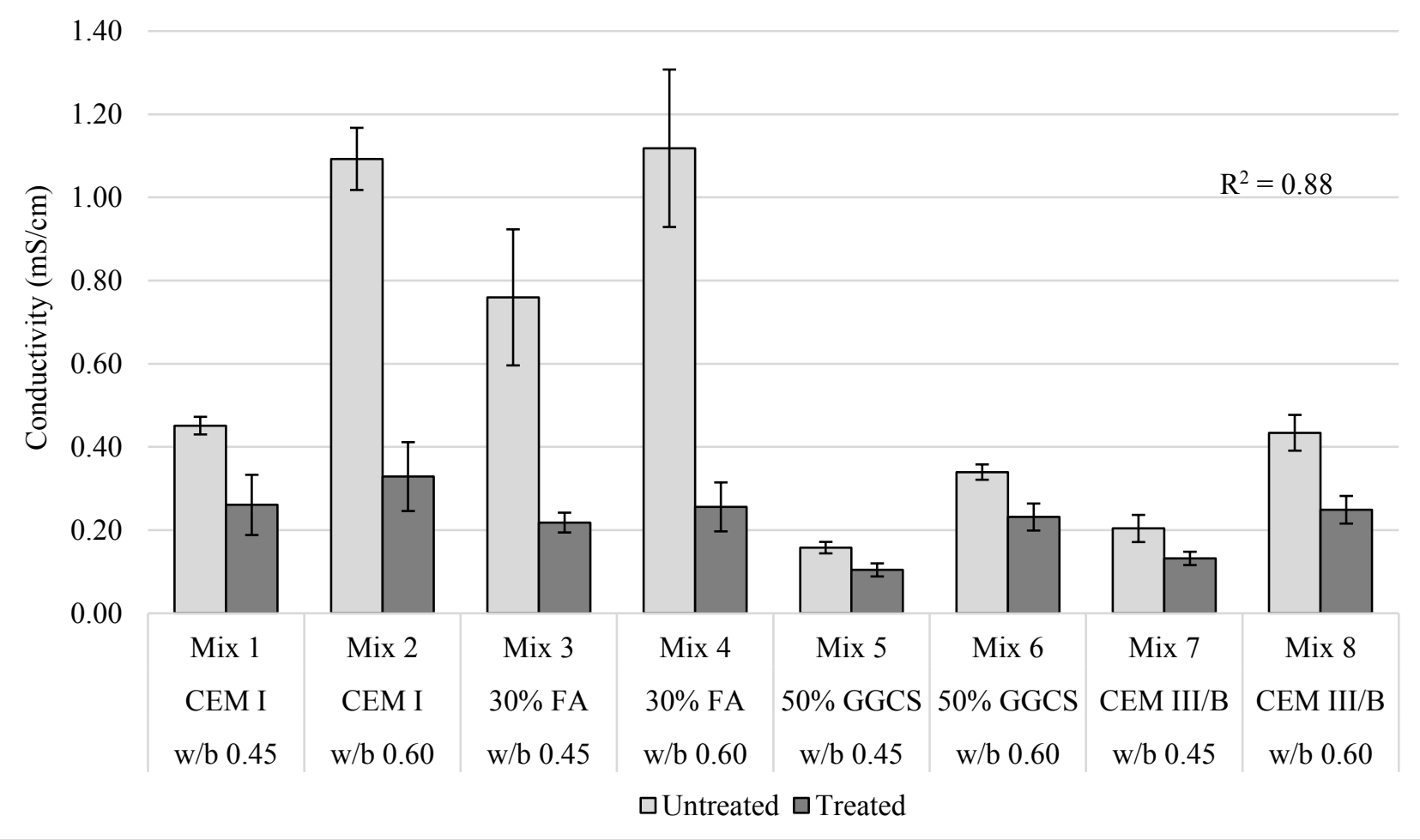

Fig. 5. Durability Index test results (uncut surfaces - CCI)

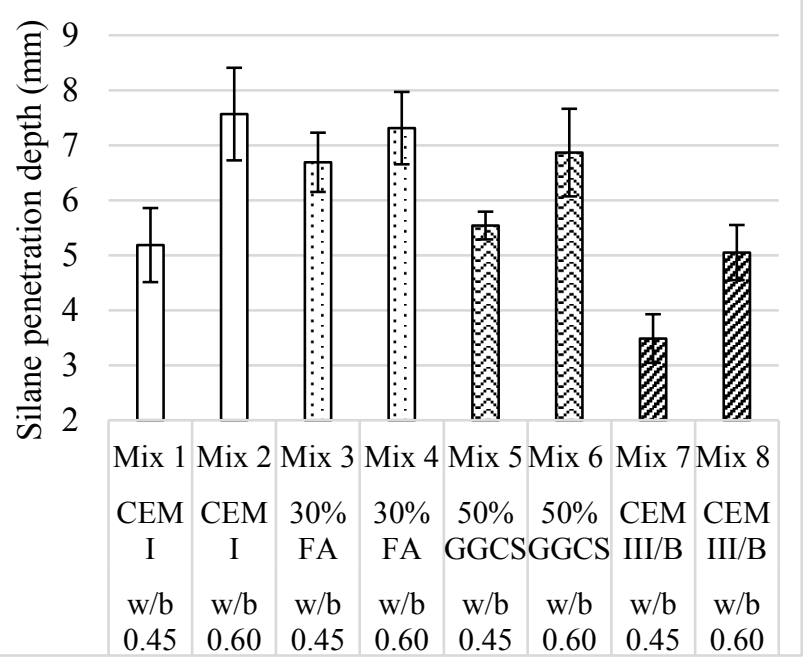

Fig. 6. Silane penetration depth

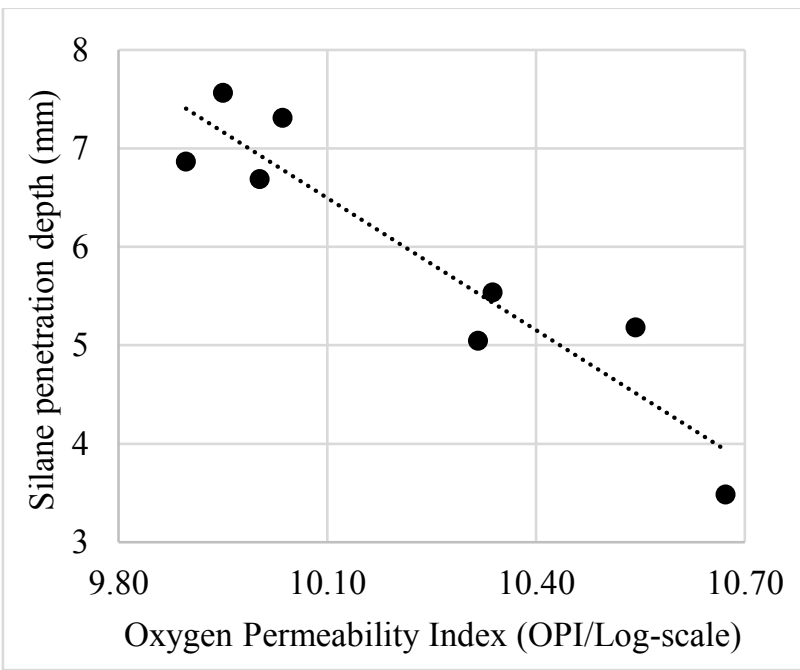

Fig. 7. Correlation between silane penetration depth and OPI 


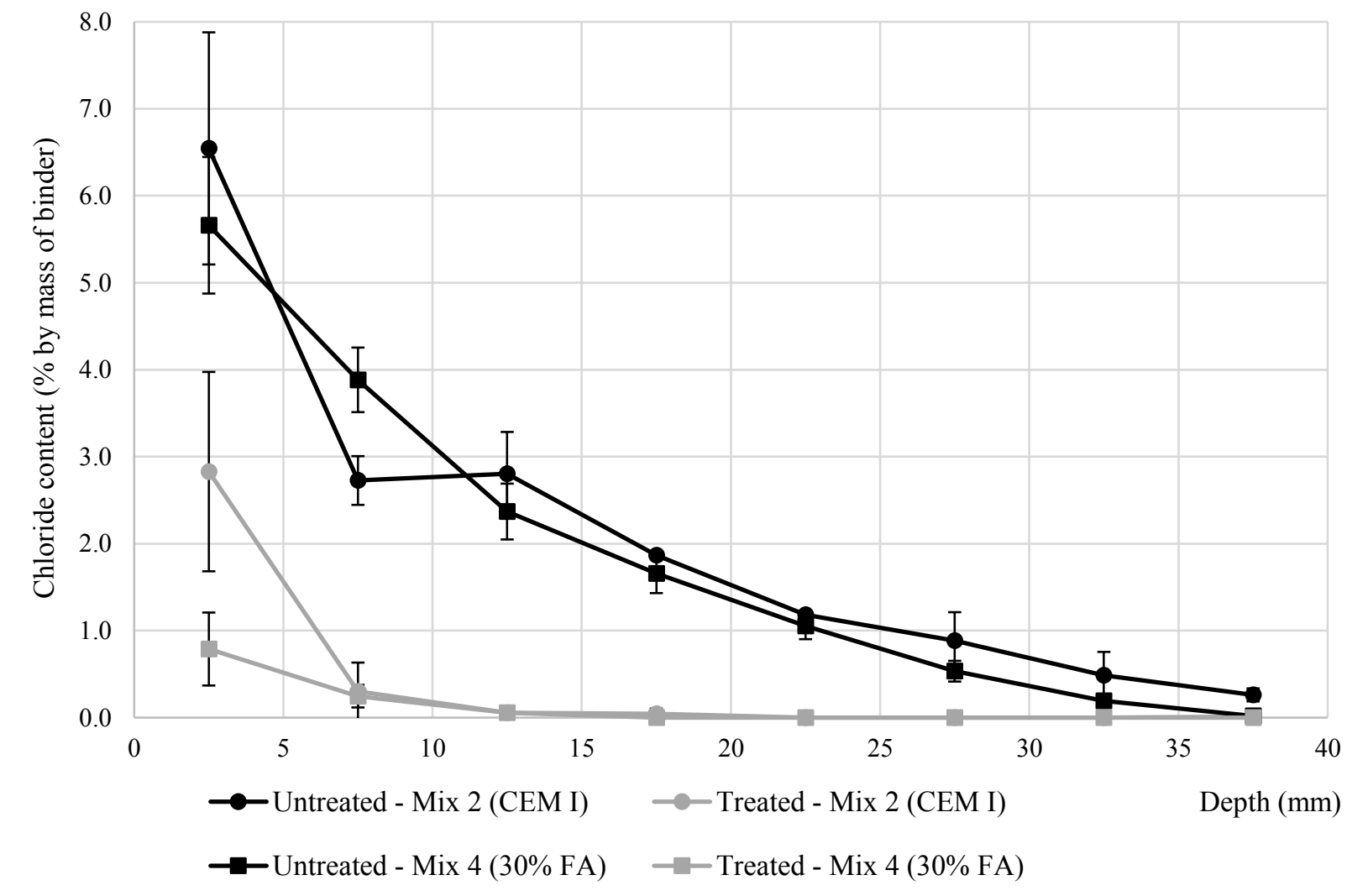

Fig. 8. Diffusion test results: CEM I and FA mixes, w/b $=0.60$

\section{Conclusions}

- The silane penetration depth was strongly dependent on the quality (porosity) of the near surface zone as deeper penetration was observed in the higher $w / b$ concrete mixes. A near linear correlation between Oxygen Permeability Index values and silane penetration was recorded, indicating that the OPI test is an excellent method to assess likely penetration depth of the product.

- Silane impregnation improved the transport properties (lowered sorptivity and conductivity) of the concrete mixes, indicating a significant decrease in penetrability. Similarly, in relation to chloride ingress, chloride surface concentrations and chloride penetration depth in general were reduced for all treated concrete mixes; chloride ingress in treated concrete was considerably lower, compared to untreated concrete.

- For practical applications, the results indicate that the durability of reinforced concrete structures in marine environments (splash/spray zone, airborne exposure), regardless of the binder type, can effectively be improved using hydrophobic impregnation, assuming proper surface preparation and application methods.

\section{References}

1. L. Bertolini, B. Elsener, P. Pedeferri, E. Redaelli, \& R.B. Polder. Corrosion of steel in concrete: prevention, diagnosis, repair. John Wiley \& Sons (2013)

2. C. Christodoulou, C.I., Goodier, S.A., Austin, J. Webb, \& G.K. Glass. Long-term performance of surface impregnation of reinforced concrete structures with silane. Construction and Building Materials. 48:708-716 (2013)

3. J. Dai, Y. Akira, F. Wittmann, H. Yokota, \& P. Zhang. Water repellent surface impregnation for extension of service life of reinforced concrete structures in marine environments: the role of cracks. Cement and Concrete Composites. 32(2):101-109 (2010)

4. M. Raupach. Concrete Repair to EN 1504: Diagnosis, Design, Principles and Practice. CRC Press (2014)

5. S. Meier \& F. Wittmann. Water repellent surface impregnation of concrete: Guidelines and recommendations. Proc. ASMES Intern. Workshop Basic Research on Concrete and Applications, F.H. Wittmann and O. Mercier. Editors, Aedificatio Publishers Freiburg, Germany. 49 (2011) 
6. Sika. New product showcase - SIKAGARD 706 THIXO. Sika Canada Inc (2016)

7. R. Tepfers. Some issues concerning concrete impregnation with silanes. Politecnico di Milano (2009)

8. X. Pan, Z. Shi, C. Shi, T. Ling \& N. Li. A review on concrete surface treatment Part I: Types and mechanisms. Construction and Building Materials. 132:578-590 (2017)

9. South African National Standard (SANS). Concrete tests - Compressive strength of hardened concrete (SANS 5863:2006). Pretoria. SABS Standards Division (2006)

10. South African National Standard (SANS). Civil engineering test methods Part CO3-2: Concrete durability index testing - Oxygen permeability test (SANS 3001-CO3:2015). Pretoria. SABS Standards Division (2015)

11. University of Cape Town (UCT). Durability Index Testing Procedure Manual. Department of Civil Engineering (2017)

12. South African National Standard (SANS). Civil engineering test methods Part CO3-3: Concrete durability index testing - Chloride conductivity test (SANS 3001-CO3:2015). Pretoria. SABS Standards Division (2015)

13. BS EN 1504-2. Products and systems for the protection and repair of concrete structures Definitions, requirements, quality control and evaluation of conformity - Part 2: Surface protection systems for concrete. British Standards Institution (BSI), United Kingdom (2004)
14. ASTM C1556-04. Standard Test Method for Determining the Apparent Chloride Diffusion Coefficient of Cementitious Mixtures by Bulk Diffusion. ASTM International, USA (2004)

15. ASTM C1152/C1152M-04. Standard Test Method for Acid-Soluble Chloride in Mortar and Concrete. ASTM International, USA (2012)

16. P.K. Mehta \& P.J. Monteiro. Concrete: microstructure, properties, and materials. McGrawHill (2006)

17. Y. Liu. Silicone Dispersions. CRC Press (2017)

18. K. Li. Durability Design of Concrete Structures: Phenomena, Modelling, and Practice. John Wiley \& Sons (2017)

19. P. Zhang, H. Shang, D. Hou, S. Guo \& T. Zhao. The effect of water repellent surface impregnation on durability of cement-based materials. Advances in Materials Science and Engineering (2017)

20. A. Johansson. Impregnation of Concrete Structures: Transportation and Fixation of Moisture in Water Repellent Treated Concrete. Doctoral dissertation, KTH (2006)

21. Y. Ballim, M. Alexander \& H. Beushausen. 'Durability of concrete', in G Owens (ed.), Fulton's Concrete Technology, Cement and Concrete institute, Midrand (2009)

22. H. Sohawon. Service life extension of reinforced concrete structures using hydrophobic impregnation. University of Cape Town (UCT) (2018) 